\title{
Employee engagement and internal branding-Two sides of the same coin?
}

\author{
Kati Suomi, Saila Saraniemi, Mervi Vähätalo, Tomi Kallio \& Terhi Tevameri
}

\begin{abstract}
This study examines the link between employee engagement and internal branding. It seeks to understand which antecedent factors healthcare professionals consider important for employee engagement and what kinds of implications this engagement-related information may have for internal branding. The study reviews the literature on employee engagement and internal branding and presents a conceptualisation of the linkage between the two concepts. The empirical portion content-analyses more than 1200 answers to open questions to examine employee engagement in the case organisation, a large private healthcare organisation in Finland. The findings suggest the following eight antecedent factors to be particularly important for healthcare professionals' employee engagement: organisational culture, reward, working environment, training, HR practices, reputation and values, communication, and physical environment. Based on the empirical and theoretical analyses it can be said that the antecedent factors of employee engagement and elements of internal branding can be considered two sides of the same coin.
\end{abstract}

\section{Keywords}

Employee engagement, internal branding, healthcare, knowledge-intensive organisations, services 


\section{Introduction}

In the post-industrial age, recruiting and retaining competent personnel can be considered one of the most important responsibilities of employers (e.g. Hillebrandt and Ivens 2013; Edlinger 2015; Tanwar and Prasad 2016). Given the shortage of competent healthcare professionals in many Western countries, once professionals are recruited, engaging them with an organisation can be considered crucial. It is well acknowledged that attracting the best talents is important, but motivating them to stay is even more so (Tanwar and Prasad 2016; see also Whelan et al. 2010). Thus, in the current study, we focus on both employee engagement and internal branding. Harter et al. (2002, p. 269) described engagement as an 'individual's involvement and satisfaction with as well as enthusiasm for work', and Maslach et al. (2001) came close to Harter et al. (2002) in suggesting that engagement constitutes employees' involvement, energy and efficacy. By internal branding we refer to 'a doctrine to ensure employees' delivery of the brand promise by shaping employees' brand attitudes and behaviours' (Punjaisri et al. 2008, p. 407). Indeed, one of the critical success factors for service organisations today is service employees' job performance enabled by engagement (Lee et al. 2014). Lee et al. (2014) suggested that employee engagement is a viable condition linking internal branding to the nurturing of job satisfaction. Internal branding also positively affects employee engagement. Despite these findings, there is surprisingly little research regarding the relationship between these two concepts, potentially due to their roots in different disciplines. Thus, in this study, we examine their fuzzy relationship in more depth. 
Ewing et al. (2002) argued that organisations operating in knowledge-intensive service industries are increasingly facing a situation in which it is easier to find skilled workers than eager customers. In the service context, employees personify a corporate brand (e.g. Iglesias et al. 2013) and can be considered 'the embodiment of the service brand' (Punjaisri et al. 2009a, 2009b). Employees' skills and knowledge are not the only important thing for the corporate brand; compatibility between the employee and the organisation (Elving et al. 2013), is also crucial for employees to 'live the brand' and become 'brand ambassadors' (Ind 2004). Particularly in the service sector, employees play the critical role of building the corporate brand not only at their workplace, but also through interactions with families, friends and networks (e.g. Morokane et al. 2016).

The literature shows a strong relationship between employee engagement and organisational performance (Lowe 2012). Similarly, internal branding impacts companies' performance (e.g. Tuominen et al. 2016; see also Iyer et al. 2018). However, little research has examined the focus of the present study: the relationship between the two internal processes of employee engagement and internal branding. Some findings have implied such a relationship, suggesting that elements of internal branding, such as negotiating and co-constructing values between management and employees, enhance employee engagement (Aggerholm et al. 2011) and that employee engagement mediates internal branding and employee-related outcomes (Lee et al. 2014). In addition, Davies et al. (2018) suggest that employees' engagement increases in line with their positive perceptions of their employer's image; the effects of these perceptions on their engagement are mediated by the employees' satisfaction.

Although the importance of internal branding is well acknowledged in service industries in general (e.g. Punjaisri et al. 2009a) and in the context of knowledge-intensive organisations in 
particular (e.g. Sujchaphong et al. 2015), few studies have examined internal branding in the context of healthcare (Gapp and Merrilees 2006; Heilmann 2010; Hytti et al. 2015), Nevertheless, this topic is highly relevant in Western countries, including Finland. Health services are increasingly required to facilitate greater opportunities to choose services and service providers according to customers' needs and preferences. This is likely to enhance competition for both employees and customers, pointing to a need to pay better attention to employee engagement.

Lee et al. (2014, p. 1376) suggested that 'internal branding should be precedent of employee engagement' Developing on this idea from a theoretical perspective, the present study aims to combine the concepts of employee engagement and internal branding in the context of healthcare. From a managerial perspective, the underlying assumption is that recognising important factors in employee engagement enables the management of healthcare organisations to enhance internal branding practices to involve employees more effectively in brand value co-creation (c.f. Saleem and Iglesias 2016). The study addresses the following research question: How are employee engagement and internal branding conceptually linked?

The next section reviews the literature on employee engagement and internal branding and provides literature-based integration of these concepts to address the study's conceptual and theoretical background. Thereafter, the data collection and methods of analysis based on the created framework are described. Next, the empirical findings section shows how healthcare professionals experience the antecedents of employee engagement and how elements of internal branding are intertwined in the same experiences. The Discussion section focuses on the theoretical and managerial contributions of the findings, following suggestions for future research 


\section{Theoretical Background}

\section{Employee engagement}

In recent years, employee engagement has received growing interest, particularly in the organisational and human resource management literature (e.g. Robertson and Cooper 2010; Rana et al, 2014), but also in the literature on psychology and healthcare (see Dagher et al. 2015). The concept originated in burnout research, which tends to examine employees' wellbeing, not just their 'unwell-being' (see Schaufeli et al. 2002). According to Robinson et al (2004), engagement is a two-way relationship between employer and employee. Using social exchange theory, Saks (2006, p. 603) interpreted Kahn's (1990) seminal article in the area, which posited that employee engagement means a condition in which employees feel obligated to integrate themselves more deeply into their role performance as repayment for the resources they have received from the organisation. Through this engagement, employees 'employ and express themselves physically, cognitively, and emotionally during role performance' (Kahn 1990, p. 694). Following this concept multidimensionality, Schaufeli et al. (2002, p. 74) provided one of the most widely cited definitions of engagement: 'a positive, fulfilling, workrelated state of mind that is characterised by vigor, dedication and absorption'. As Robertson and Cooper (2010) stated, engaged employees have positive attitudes, but also an active use of emotions and cognitions, with focus on their formal role performance (unlike in some similar constructs, such as job involvement or commitment; Saks 2006; Lee et al. 2014).

Many studies, such as that by Saks (2006), suggest that employee engagement covers both job engagement and organisational engagement, meaning that an employee has both a work role 
and a role as an organisational member. However, despite many attempts, the concept is vague and lacks clarification (Robertson and Cooper 2010; Dagher et al. 2015).

In short, literature has discussed the psychological conditions (Kahn 1990), dimensions (Schaufeli et al. 2002), work-life factors (Maslach et al. 2001), antecedents (Rana et al. 2014; Rana 2015), components (Rothbard 2001), elements (Beattie and Waterhouse 2015), determinants (Anitha 2014), outcomes (May et al., 2004; Wollard and Schuck 2011; Beattie and Waterhouse 2015; Lee et al. 2014) and consequences of employer engagement (Saks, 2006).

For the purposes of this study, we are particularly interested in the antecedents of employee engagement for understanding what makes an employee achieve a 'positive, fulfilling workrelated state of mind' (see Schaufeli et al. 2002). According to earlier literature, employee engagement has positive consequences for employee and organisation alike. For example, in the healthcare context, Lowe (2012) found that high employee engagement is related to retention, patient-centred care, a patient safety culture and a positive employee evaluation of the quality of care or services.

Several conceptual and empirical papers have identified various antecedents (or elements) of employee engagement. Beattie and Waterhouse (2015) suggested the following elements of employee engagement: feeling valued and having a voice, job satisfaction and meaningful work, supportive culture, senior management style and vision, line management support, communication, teamwork and supportive colleagues, supporting health and wellbeing, performance management and reward, equality and learning. Anitha (2014) found that working environment, leadership, team and co-worker relationship, training and career development, 
compensation programme, organisational policies and procedures, and workplace wellbeing were determinants of employee engagement, which we see as paralleling the antecedents of employee antecedents.

Saks (2006) also mentioned five antecedents of employee engagement. First, job characteristics include challenges, variety of tasks, opportunities to make important contributions, time pressure and quantitative job demands (see also Kahn 1990; Maslach et al. 2001). Secondly, employees' perceptions of organisational support, and thirdly, perceived supervisor support, rewards and recognition can be considered antecedents of employee engagement. Fourthly, procedural justice, or an employee's perception of fairness in allocating resources, can be considered an antecedent of employee engagement. Finally, Saks (2006) suggested distribution justice, or perceived fairness of outcomes or decisions made, as an antecedent of employee engagement. Further, Welch (2011) highlighted communication as an important antecedent of employee engagement and maintained that it would be useful for employers to consider personnel's communication needs in accordance with differences in employee engagement (see also Saks 2006).

In their conceptual paper, Rana et al. (2014) consolidated several antecedents of employee engagement, including job design and characteristics, supervisor and co-worker relationships, workplace environment and human resource development practices. Further, Rana (2015) identified employee power, information, reward and knowledge as antecedents of employee engagement. Next, we review the literature on internal branding to address the relationship between these two concepts.

\section{Internal branding}


Prior studies have noted the importance of employees in building strong service brands (e.g., Löhndorf and Diamantopoulos 2014). Building a consistent corporate brand in the service context might be challenging, as services (e.g. healthcare) are intangible and complex in nature (Zeithaml et al. 2012), in addition to being constructed of people-based processes, through which employees may either enhance or damage a corporate brand (e.g. Roper and Fill 2012). Accordingly, firms' employees may be regarded as internal customers who deliver brand promise and co-create brand value through their interactions with customers and other stakeholders (e.g. Merz et al. 2009; see also Davies and Chun 2002). Therefore, internal branding can be deemed important because it ensures that employees deliver the brand promise to customers (de Chernatony and Harris 2000; Bergstrom et al. 2002; Foster et al. 2010; Hytti et al. 2015; Kuoppakangas et al. 2019).

The extant literature describes the rationale and reasons for internal branding in terms of underlining the importance of 'selling the brand inside'. This means that companies need to pay attention to internal branding to their employees, particularly when the company is facing a major challenge or change and when employees are searching for direction. Furthermore, companies should align their internal and external branding, bring the brand alive for employees and create a connection for them on an emotional level with the brand (e.g. Mitchell, 2002; Hytti et al. 2015; Kuoppakangas et al. 2019). With regard to the consequences of internal branding, it has been argued that internal branding affects the extent to which employees identify with, commit to, and show loyalty toward the brand, as well as the extent to which employees behave in ways that are consistent with the delivery of the company's brand promise (Punjaisri et al. 2009a; Punjaisri and Wilson 2011). Moreover, internal branding indirectly affects brand performance (Tuominen et al. 2016; Iyer et al. 2018) and market performance 
(Tuominen et al. 2016). However, for the purposes of this study, we are particularly interested in the elements of internal branding that, according to the literature (e.g. Aggerholm et al. 2011; Lee et al. 2014), seem to be conceptually close to the antecedents of employee engagement.

Wallström et al. (2008) describe the internal brand building process as comprising three stages, related to brand audit, brand identity and brand position statement. Punjaisri and Wilson (2011) highlighted internal communication and training as key elements of internal branding. Internal communication consists of both formal and informal communications between employees and management (Dean et al. 2016), and it is vital for building a culture of transparency and engaging employees in the organisation and its vision (Mishra et al. 2014). Concretely, it includes newsletters, daily briefings and group meetings, for example (Punjaisri and Wilson, 2011). Further, training may include programmes, courses and orientation (Punjaisri and Wilson 2011). In addition to internal communication and training, Lee et al. (2014) added a third element of internal branding: namely, rewards. Like training, rewards represent human resource practices. Rewards may include reward systems and recognition schemes (Punjaisri and Wilson 2007).

Further, Saleem and Iglesias (2016, p. 50) defined internal branding as the process through which organisations integrate five elements - brand ideologies, leadership, human resource management (HRM), internal brand communications and internal brand communities - as a strategy to enable employees to co-create brand value with stakeholders. As such, the definition approaches internal branding from a wide perspective, assuming that this strategy occurs in a supportive organisational culture (ibid, p. 50). Brand ideologies reflect a brand's vision, mission, aims, norms and values. Brand leadership refers to leaders who deliver a clear brand ideology and enable a shared understanding of the brand promise. Brand-centred HRM relates to recruiting and selecting employees whose values are compatible with the brand's values. Internal brand communication is linked to such issues as effective internal communication and 
treating employees like customers. Finally, internal brand communities refer to both physical and online communities that enable employees to identify with the brand in question (Saleem and Iglesias 2016).

To summarise the above discussion, it appears that, in prior literature, internal branding targets both cognitive and behavioural levels of change among employees (c.f. Lee et al. 2014) and has been approached primarily as a brand-centred organisational strategy and culture.

Integrating employee engagement and internal branding

The review of employee engagement and internal branding illustrates several concrete connections between the two concepts. In Table 1, we summarise the overlapping elements of employee engagement and internal branding. This clarifies that elements of internal branding, both actions and conditions, precede employee engagement. Recognising both aspects in the management of a service organisation enables a holistic understanding of employee retention.

Table 1 Comparison of the antecedents of employee engagement and the elements of internal branding

\begin{tabular}{|c|c|}
\hline Antecedents of employee engagement & Elements of internal branding \\
\hline \multicolumn{2}{|c|}{ Organisational culture } \\
\hline $\begin{array}{l}\text { Supportive culture (Beattie and Waterhouse 2015) } \\
\text { Feeling valued and having a voice (Beattie and } \\
\text { Waterhouse 2015) } \\
\text { Perceived fairness (Maslach et al. 2001) } \\
\text { Equality (Beattie and Waterhouse 2015) } \\
\text { Employee satisfaction (Davies et al. 2018) }\end{array}$ & $\begin{array}{l}\text { Supportive corporate culture } \\
\text { (Saleem and Iglesias 2016) } \\
\text { Leadership (Vallaster \& de Chernatony 2006) }\end{array}$ \\
\hline
\end{tabular}




\begin{tabular}{|c|c|}
\hline $\begin{array}{l}\text { Rewards and recognition (Maslach et al. 2001) } \\
\text { Reward (Rana 2015) } \\
\text { Reward (Beattie and Waterhouse 2015) } \\
\text { Compensation programme (Anitha 2014) }\end{array}$ & Reward (Lee et al. 2014) \\
\hline \multicolumn{2}{|c|}{ Working environment } \\
\hline $\begin{array}{l}\text { Working environment (Anitha 2014) } \\
\text { Team and co-worker relationships } \\
\text { (Anitha 2014) } \\
\text { Workplace environment (Rana et al. 2014) } \\
\text { Supervisor and co-worker relationships (Rana et } \\
\text { al, 2014) } \\
\text { Community and social support (Maslach et al. } \\
2001 \text { ) } \\
\text { Teamwork and supportive colleagues (Beattie and } \\
\text { Waterhouse 2015) } \\
\text { Positive work environment (Lee et al. 2014) }\end{array}$ & Internal brand community (Saleem and Iglesias 2016) \\
\hline \multicolumn{2}{|c|}{ Training } \\
\hline $\begin{array}{l}\text { Training and career development (Anitha 2014) } \\
\text { Learning (Beattie and Waterhouse 2015) }\end{array}$ & $\begin{array}{l}\text { Training (Punjaisri and Wilson 2011) } \\
\text { Training (Lee et al. 2014) } \\
\text { Training (Roper and Fill 2012) }\end{array}$ \\
\hline \multicolumn{2}{|c|}{ HR practices } \\
\hline $\begin{array}{l}\text { Human resource development practices (Rana et } \\
\text { al. 2014) } \\
\text { Supporting health and wellbeing (Beattie and } \\
\text { Waterhouse 2015) }\end{array}$ & $\begin{array}{l}\text { Brand-centred human resource management } \\
\text { (Saleem and Iglesias 2016) } \\
\text { Human resource management } \\
\text { (Aurand et al. 2005) }\end{array}$ \\
\hline \multicolumn{2}{|c|}{ Reputation and values } \\
\hline $\begin{array}{l}\text { Values (Maslach et al. 2001) } \\
\text { Positive image of employer among employees } \\
\text { (Davies et al. 2018) }\end{array}$ & $\begin{array}{l}\text { Brand ideologies (Saleem and Iglesias 2016) } \\
\text { Brand leadership (Saleem and Iglesias 2016) } \\
\text { Shared meanings and corporate values (Roper and } \\
\text { Fill 2012) }\end{array}$ \\
\hline \multicolumn{2}{|c|}{ Communication } \\
\hline $\begin{array}{l}\text { Information (Rana 2015) } \\
\text { Knowledge (Rana 2015) } \\
\text { Communication (Beattie and Waterhouse 2015) }\end{array}$ & $\begin{array}{l}\text { Internal brand communication } \\
\text { (Saleem and Iglesias 2016) } \\
\text { Internal communication (Lee et al. 2014) } \\
\text { Internal communication (Punjaisri and Wilson 2011) } \\
\text { Internal communication (Roper and Fill 2012) }\end{array}$ \\
\hline
\end{tabular}

As illustrated in Table 1, employee engagement and internal branding are closely related and contain several overlapping elements that relate to organisational culture, rewards, working environment, training, HR practices, reputation and values, and communication. It seems that the basic difference between the concepts is internal branding's stronger emphasis on a brandcentred perspective. Furthermore, looking at these elements from an internal branding 
perspective implies a more strategic approach for management that concerns the organisation and its brand as a whole, stemming with and spreading from the top-management level. By contrast, the employee engagement perspective seems to focus far more on individual factors or tools of HRM while also being more nuanced and employee-centred in its approach. Furthermore, with regard to internal branding, there is an underlying assumption, typical of marketing, that embraces customer and stakeholder orientation, and considers internal activities directly or indirectly affecting customer relationships (e.g. Grönroos 2006). Ultimately, it is suggested that elements of internal branding enhance employee engagement (Aggerholm et al. 2011), and that both concepts are reflected in the motivation to continue in the work (see Tanwar and Prasad, 2016).

\section{Data collection and analysis}

The data used in this study were collected from a large private healthcare organisation. The organisation operates in Finland and has numerous clinics around the country employing several thousand personnel. The personnel consist of employees and practitioners, who work entrepreneurially. The first group - employees_comprises such healthcare professionals as nurses, physiotherapists and physicians. The second group consists primarily of specialised physicians and, to a smaller extent, other healthcare professionals, such as therapists, who both work for the company a few hours a month or more. Further, it was typical for practitioners in this study to work simultaneously in one or several other healthcare organisations in either the public or the private sector. The study data were gathered during the spring of 2016 as part of a larger research project. The electronic survey targeted physicians, nurses and related healthcare professionals who were working for the company at the time of the survey. 
The physicians' group covered the following personnel groups: general practitioners, specialist and specialising doctors and dentists. The group of nurses consisted of nurses, physiotherapists, radiographers, laboratory nurses and occupational health nurses. The respondents worked as either employees or practitioners in the studied healthcare organisation. Thus, the study covered the total sample of the above-mentioned groups. Three survey reminders were sent to catch those recipients who worked for the company only rarely. The questionnaire was sent through email to all representatives of the above-listed personnel groups: 3782 people altogether. In total, 772 individuals responded. The overall response rate for the survey was $20.4 \%$, which can be considered adequate in comparison to recent studies (e.g. Boon et al, 2011). The current study concentrates on respondents' verbal answers to the following two open-ended questions, which produced more than 1200 individual answers:

- Which factors (in general) increase or could increase your engagement with an employer (if you are a practitioner, with your working place)? $(\mathrm{N}=631)$

- Which factors (in general) decrease or could decrease your engagement with an employer (if you are a practitioner, with your working place)? $(\mathrm{N}=611)$

The answers reflect both the present state in the studied organisation and the antecedent factors that increase/could increase or decrease/could decrease engagement more generally. Through these responses, we were able to gain knowledge about the antecedents respondents believed to affect their employee engagement.

The data gathered through the two open-ended questions were analysed qualitatively, using thematic analysis (Braun and Clarke 2006) and applying abductive logic. Although a tentative theoretical framework based on the literature review was implemented in the early phases of 
the research process, it was developed alongside an analysis of the empirical data (Dubois and Gadde 2002). In the analysis, attention was paid to what was said, rather than how it was said. The first phase of the data analysis began with a careful reading of all verbal answers to the two open questions. The data were then coded inductively to examine which antecedents the respondents considered important for employee engagement. This phase identified numerous detailed items (Table 2), which were at a low level of abstraction.

The coding of the data guided the researcher to notice that the answers to the two questions appeared to be reversed. Namely, issues believed to increase (or that could increase) employee engagement, when working well, were largely the same as those believed to decrease (or that could decrease) engagement if not functioning well. Consequently, in a third phase, the data collected by the two questions were treated as one and, thus, combined. In the fourth phase, the data were further condensed. This procedure yielded 26 categories of employee engagement antecedents, which are presented in Table 2.

In the fifth and the last phase of the analysis, in the spirit of abductive reasoning (Dubois and Gadde 2002; Kovácks and Spens 2005), the 26 categories were reviewed in light of the theoretical categorisation presented in Table 1. The themes were incorporated into Table 1's seven wider theoretical themes to further abstract the empirical findings. In order to increase reliability of analysis, the authors discussed the findings (see Patton 2002). The authors noted that, of 26 empirical categories, one category—namely, physical environment—did not fit any of the theoretical categories, as the theoretical category of "working environment" (Anitha 2014) did not include elements of the physical environment. Thus, this category is presented separately among the eight categories discussed more closely in the following section. 


\section{Empirical findings}

This section describes how healthcare professionals describe the antecedents of employee engagement. Table 2 presents these antecedents in detail, along with their connection to the theoretical framework of this study. The connection between the antecedents of employee engagement and elements of internal branding will be discussed further in the Discussion section.

Table 2. Comparison of the antecedents of employee engagement and the elements of internal branding augmented with empirical data from healthcare professionals

\begin{tabular}{|c|c|c|}
\hline $\begin{array}{c}\text { Antecedents of employee } \\
\text { engagement }\end{array}$ & $\begin{array}{c}\text { Empirical findings of } \\
\text { antecedents of employee } \\
\text { engagement }\end{array}$ & Elements of internal branding \\
\hline \multicolumn{3}{|c|}{ Organisational culture } \\
\hline \multirow{5}{*}{$\begin{array}{l}\text { Supportive culture (Beattie and } \\
\text { Waterhouse 2015) } \\
\text { Feeling valued and having a } \\
\text { voice (Beattie and Waterhouse } \\
\text { 2015) } \\
\text { Perceived fairness (Maslasch et } \\
\text { al. 2001) } \\
\text { Equality (Beattie and Waterhouse } \\
2015 \text { ) }\end{array}$} & $\begin{array}{l}\text { Management culture, leadership } \\
\text { skills, change management, } \\
\text { listening, feedback, regard, } \\
\text { thanking, fairness, ways of } \\
\text { monitoring one's performance, } \\
\text { "invisible work" }\end{array}$ & \multirow[t]{5}{*}{$\begin{array}{l}\text { Supportive corporate culture } \\
\text { (Saleem and Iglesias 2016) }\end{array}$} \\
\hline & $\begin{array}{l}\text { Duration of one's contract, } \\
\text { certainty of continuity, secure jobs, } \\
\text { sufficiency of patients of } \\
\text { practitioners, certainty of one's } \\
\text { income, staff turnover }\end{array}$ & \\
\hline & Respect, appreciation & \\
\hline & Fairness, equality & \\
\hline & Flexibility & \\
\hline \multicolumn{3}{|c|}{ Reward } \\
\hline \multirow{3}{*}{$\begin{array}{l}\text { Rewards and recognition } \\
\text { (Maslach et al. 2001) } \\
\text { Reward (Rana 2015) }\end{array}$} & Salary, income & \multirow[t]{3}{*}{ Reward (Lee et al. 2014) } \\
\hline & Reward & \\
\hline & Rent percent (for practitioners) & \\
\hline
\end{tabular}




\begin{tabular}{|c|c|c|}
\hline $\begin{array}{l}\text { Reward (Beattie and Waterhouse } \\
\text { 2015) } \\
\text { Compensation programme } \\
\text { (Anitha 2014) }\end{array}$ & $\begin{array}{l}\text { Occupational healthcare, the way } \\
\text { in which eating at workplace is } \\
\text { arranged, luncheon vouchers, } \\
\text { coffee, parking }\end{array}$ & \\
\hline \multicolumn{3}{|c|}{ Working environment } \\
\hline \multirow{2}{*}{$\begin{array}{l}\text { Working environment (Anitha } \\
\text { 2014) } \\
\text { Team and co-worker } \\
\text { relationships } \\
\text { (Anitha 2014) } \\
\text { Workplace environment (Rana et } \\
\text { al. 2014) } \\
\text { Supervisor and co-worker } \\
\text { relationships (Rana et al. 2014) } \\
\text { Community and social support } \\
\text { (Maslach et al. 2001) } \\
\text { Teamwork and supportive } \\
\text { colleagues (Beattie and } \\
\text { Waterhouse 2015) } \\
\text { Positive work environment (Lee } \\
\text { et al. 2014) }\end{array}$} & $\begin{array}{l}\text { Cooperation, work community, } \\
\text { support from work community, } \\
\text { sense of community, multi- } \\
\text { professional cooperation, support } \\
\text { from other staff, sharing know- } \\
\text { how, number and quality of } \\
\text { assisting staff, "internal } \\
\text { customership" }\end{array}$ & \multirow[t]{2}{*}{$\begin{array}{l}\text { Internal brand community } \\
\text { (Saleem and Iglesias 2016) }\end{array}$} \\
\hline & Workplace climate & \\
\hline \multicolumn{3}{|c|}{ Training } \\
\hline $\begin{array}{l}\text { Training and career } \\
\text { development (Anitha 2014) } \\
\text { Learning (Beattie and } \\
\text { Waterhouse 2015) }\end{array}$ & $\begin{array}{l}\text { Orientation, training, mentoring, } \\
\text { possibilities to develop, developing } \\
\text { of skills, career advancement, } \\
\text { career paths }\end{array}$ & $\begin{array}{l}\text { Training (Punjaisri and Wilson, } \\
\text { 2011) } \\
\text { Training (Lee et al. 2014) }\end{array}$ \\
\hline \multicolumn{3}{|c|}{ HR practices } \\
\hline \multirow{8}{*}{$\begin{array}{l}\text { Human resource development } \\
\text { practices (Rana et al. 2014) } \\
\text { Supporting health and } \\
\text { wellbeing (Beattie and } \\
\text { Waterhouse 2015) }\end{array}$} & Human resources & \multirow{8}{*}{$\begin{array}{l}\text { Brand-centred human resource } \\
\text { management } \\
\text { (Saleem and Iglesias 2016) }\end{array}$} \\
\hline & $\begin{array}{l}\text { Balance of work and leisure time } \\
\text { Work well-being }\end{array}$ & \\
\hline & $\begin{array}{l}\text { Possibilities to influence one's } \\
\text { working times and holidays to } \\
\text { meet the needs of one's family life, } \\
\text { flexible working hours, own health }\end{array}$ & \\
\hline & $\begin{array}{l}\text { Location, distance from one's } \\
\text { family }\end{array}$ & \\
\hline & $\begin{array}{l}\text { Content of one's work, possibilities } \\
\text { to influence one's tasks, autonomy, } \\
\text { ability to engage in high-quality } \\
\text { patients' care, one's work, } \\
\text { meaningfulness of one's work, } \\
\text { challenges }\end{array}$ & \\
\hline & $\begin{array}{l}\text { Invoicing, secretary services, } \\
\text { support services, booking of } \\
\text { appointments }\end{array}$ & \\
\hline & IT and electronical services & \\
\hline & Instructions/guidelines, processes & \\
\hline \multicolumn{3}{|c|}{ Reputation and values } \\
\hline \multirow[t]{3}{*}{ Values (Maslach et al. 2001) } & $\begin{array}{l}\text { Organisational reputation, } \\
\text { corporate brand }\end{array}$ & \multirow{3}{*}{$\begin{array}{l}\text { Brand ideologies (Saleem and } \\
\text { Iglesias 2016) } \\
\text { Brand leadership (Saleem and } \\
\text { Iglesias 2016) }\end{array}$} \\
\hline & $\begin{array}{l}\text { Ethics in operations, ethical } \\
\text { payment of taxes, honesty, meeting } \\
\text { of organisation's and one's own } \\
\text { values, goals, ability to work in } \\
\text { accordance with one's professional } \\
\text { ethics }\end{array}$ & \\
\hline & Quality of patient care, expertise & \\
\hline
\end{tabular}




\begin{tabular}{|l|l|l|}
\hline $\begin{array}{l}\text { Information (Rana 2015) } \\
\text { Knowledge (Rana 2015) } \\
\text { Communication (Beattie and } \\
\text { Waterhouse 2015) }\end{array}$ & $\begin{array}{l}\text { Communication, openness, } \\
\text { interaction, sharing of knowledge }\end{array}$ & $\begin{array}{l}\text { Internal brand communication } \\
\text { (Saleem and Iglesias 2016) } \\
\text { Internal communication (Lee et } \\
\text { al. 2014) } \\
\text { Internal communication } \\
\text { (Punjaisri and Wilson 2011) }\end{array}$ \\
\hline \hline \multicolumn{2}{|c|}{ Physical environment } \\
\hline & $\begin{array}{l}\text { Equipment, instruments, working } \\
\text { spaces, breakrooms, inside air/air } \\
\text { conditioning, ergonomics, the } \\
\text { quality of laboratory services, } \\
\text { location, traffic connections }\end{array}$ & \\
\hline
\end{tabular}

\section{Organisational culture}

The data showed that organisational culture was perceived as important for employee engagement. While organisational culture was reflected either explicitly or implicitly from numerous different perspectives, it was particularly emphasised in relation to issues concerning leadership and management (see also Hatch and Schultz 1997; Fombrun et al. 2015). The respondents, for instance, deemed it important for one to be able to autonomously define her/his tasks. Accordingly, managers' interference in irrelevant or minor details of work tasks (socalled micro-management) was believed to decrease engagement. For healthcare professionals in this study, being involved in decision-making in the workplace was important. Many mentioned having a voice, emphasising that they would appreciate if managers truly listened to personnel. Respondents felt that, since they knew the content of the work, they should be listened to when developing guidelines and protocols. For example, one of the respondents stated that, in case of employee engagement, 'guidelines from the top [of the company] which are not explained, and employees have not been heard of when planning them' (employee) had a negative effect.

A supportive culture, in terms of showing concern for employee well-being, encouraging them and showing positive regard for employees, was considered crucial for employee engagement. 
As one employee emphasised feeling valued: 'It is important to feel that one's work is important.' Furthermore, in a big company, the employees felt it necessary to feel appreciated, and not just one of thousand. As one employee described, companies were 'treating personnel (professionals) as conveyor belt workers... Not trusting them [decreases employee engagement]' (employee).

Further, the respondents emphasised fairness and equality among both employees and supervisors. They indicated the importance of management being interested in employees' well-being and being aware of how individuals are doing in ways other than those based on numbers. In fact, the respondents mentioned the management's concentration on monitoring the number of patients and resulting profits as problematic. Conflicts were considered likely to occur if companies did not live the brands they promoted. As one employee pointed out: 'As we are advertising "“A healthy employee does his/her work better”, could X [case company] itself set an example of this?' (employee).

Further, respondents mentioned that relocating personnel from one unit to another and continuous staff reduction negotiations created uncertainty and caused the best employees to switch to other companies. Moreover, employers should have a good understanding of the requirements of the work. For example, they should arrange enough time to conduct the paperwork. Some of the respondents mentioned continuous changes and changes in rules concerning work practices as negatively impacting engagement.

Reward 
Not surprisingly, salary level was considered remarkably important for engagement by numerous employees. Salary was discussed particularly in relation to rewards and recognition for high work requirements, as the extract below demonstrates:

Better salary [would increase engagement] because the job description is more demanding here than in the public sector, and even with increments included, I get the same as I would get in the public sector. Why would I continue working here and doing more demanding tasks, when I could do easier work in the public sector and get the same salary or sometimes even more? ...Particularly when the employer pressures all the time towards even more efficient work and tasks that do not relate to my work. (employee)

In addition to salary level, respondents mentioned that they would appreciate rewards based on experience, education and other achievements. Indeed, with respect to compensation programmes, respondents felt that employees should be rewarded for good work input and special skills.

Practitioners mentioned the rent percent of the infrastructure and the quality of the services it covers as crucial for their engagement. Rent percent is the percentage practitioners pay a company to have their doctor's appointments on the company's premises and to use the company's facilities in terms of equipment, treatment rooms, and support services. The organisation's current percent was considered rather high. According to respondents, increasing rent would have a negative impact on engagement. Rent percent was discussed by numerous respondents who were physicians and practitioners at the company. The practitioner's obligation to follow the level of customer fees determined by the employer company was also mentioned as negatively impacting practitioners' engagement. Just as employees discussed 
desires related to their salaries, practitioners discussed their incomes in terms of a confidence in attracting a sufficient number of clients to ensure a stable income.

\section{Working environment}

Working environment and cooperation were considered important for employee engagement. In a multi-professional environment, good team and co-worker relationships were emphasised. Warm and friendly atmosphere and support from colleagues were considered important for working environment and, thus, for engagement. Patient care was seen as involving cooperation, such that a multi-professional team should support one another and collaborate seamlessly to support a patient's wellbeing. Thus, a sense of community and social support was deemed important. Particularly, practitioners emphasised the number and quality of support staff. In this context, a good spirit of internal customership, a clear division of labour and mutual appreciation were considered important. A competent community was also considered important, as the whole care chain aimed to achieve what was best for patients and customer firms of occupational healthcare. Further, working in a community was deemed as one reason for practitioners to work simultaneously in the public sector: In the public sector, one gets more support from colleagues, as there are almost always other physicians available in both the same and other medical specialties. The importance of a positive work environment and supportive colleagues was illustrated in the following extract:

Respect for all areas of [healthcare] work and seamless collaboration in multiprofessional work environment [effect positively in employee engagement]. (employee)

Respondents mentioned a feeling of inequality as decreasing engagement in terms of both supervisor and co-worker relationships. They saw inequalities between both management and staff and physicians and nurses. In addition, some practitioners mentioned the importance of an 
equal division of customers among specialists in the same branch of medicine. In contrast, 'too many practitioners, and no one has sufficient number of patients' (practitioner) was regarded as having negative impact on engagement.

However, the employees faced the opposite challenge. They emphasised the importance of assigning sufficient staff to shifts to avoid an overload of work. Furthermore, employees hoped that management and employers would be equally flexible. They also mentioned haste as negatively impacting engagement, particularly as healthcare work requires special accuracy.

\section{Training}

Training and career development were considered important for increasing engagement. The respondents mentioned the importance of continuous development and learning to retain professional skills and develop new skills. Possibilities for career development were also emphasised. The respondents also highlighted the importance of new employees' orientation and training. As one practitioner pointed out:

I would appreciate possibilities for young general practitioners to consult more experienced colleagues. For example, in Y [competitor's name], there are named tutorphysicians, who one can call to. (practitioner)

\section{Human resource practices}

As a broad category of human resource practices, issues regarding work-life balance, working tasks and support functions were defined. Indeed, balancing work and other areas of life was believed to enhance employee engagement. Work-life balance and wellbeing were reflected in 
employers' practices to enhance employees' abilities to influence their working times and hours to fit their schedules: 'An employee who feels good shares positivity around him/her and thus it is nice to work with this kind of person' (practitioner). Indeed, supporting health was reflected in one's ability to engage in his/her work.

With respect to employee engagement, the content of one's work-namely, the 'ability to focus as much as possible to basic task [of a physician]' (practitioner) and having an interesting and meaningful work - was considered very important by the healthcare professionals surveyed in this study. Respondents highlighted possibilities to work independently, have autonomy and schedule one's own calendar. They also mentioned the ability to engage in high-quality patient care, so that 'service would be as effective and high-class as possible' (practitioner), as enhancing engagement.

Support functions were discussed in terms of invoicing and secretary services. The respondents mentioned fluency of practicalities in terms of appointment bookings and workable IT software. The respondents described electronic patient records or other practical matters not working as frustrating and, thus, hindering patient care. Further, practitioners mentioned the promptness and accuracy of the rendering of accounts. The importance of support functions in increasing engagement is illustrated below:

Developing of fluency of all such support functions which enable a physician's concentration on diagnostics of a patient's symptoms, and care and sets the physician free from tasks related to statistics, and continuously increasing 'electronic paper works'... Many things could be allocated to support personnel. In my opinion, I don't get enough value for the rent that I pay. (practitioner) 
Reputation and values

The respondents highly appreciated the possibility to work in accordance with their professional values and ethics and that practices were generally ethically acceptable. Indeed, healthcare professionals considered themselves primarily professionals and not 'salesmen'. The respondents mentioned that they did not like an excessive marketing orientation, in terms of an open and hard pursuit of profits. As examples of this, the respondents mentioned high office fees and expensive laboratories, which could increase patient costs to an almost 'unbearable level'.

Some of the respondents mentioned the problem of balancing customer satisfaction and highquality patient care. The goal of $100 \%$ customer satisfaction was considered unreasonable and even unethical in healthcare, although this sentence was used as slogan on the company's website. Thus, the implementation of external brand communication raised concerns regarding the ethics of brand ideology.

Some of the respondents mentioned the organisation's reputation as important for their engagement. Respondents discussed their relationship with the organisation's reputation and brand from different perspectives:

A bad brand, too obvious pursuit for economic benefit [decreases employee engagement]. Although we all aim at it, a company must stand on ethically solid ground and we, as employees, should be encouraged towards that. (practitioner)

A willingness to care about the organisation's reputation and service promises weakens, if we as employees are not taken care of. (employee) 


\section{Communication}

Numerous respondents felt that, in the studied organisation, internal communication was inadequate and sometimes even contradictory. According to respondents, this negatively impacted engagement. Respondents felt that 'enhancing the information flow, in particular in relation to one's own workplace' (practitioner) would support employee engagement. An additional problem was that respondents lacked time to read and internalise the information. As a consequence, it was considered 'embarrassing that customers sometimes know more about what is happening in this house than yourself' (practitioner).

Sometimes, the internal communication was considered contradictory, as the following extract illustrated: 'There is communication, like: "do your job in entrepreneurial way", but at the same time our calendars are controlled in 'fear' that someone has too long lunch breaks' (practitioner). This, according to respondents, negatively impacted engagement.

Finally, the respondents did not find all external brand communication appealing and comprehensible. As one practitioner stated: '[the company has] absurd health-illness claims in advertising'.

\section{Physical environment}

The respondents discussed physical environment actively, particularly in terms of the quality and modernity of the medical equipment. Physical environment was related to keeping up with competition between other players in private healthcare sector and ensuring high-quality healthcare. Respondents in the group of practitioners directly related their requirements 
concerning the quality of equipment and instruments to their rent percent, speaking in terms of 'value for money'. Their answers mentioned high-quality equipment (e.g. for ultrasound and blood sampling). Functionality and speed of laboratory and x-ray devices were also highlighted, as were possibilities to order a diverse variety of medical examinations. Respondents mentioned adequate instruments in treatment rooms and clear responsibilities for maintenance as important issues to increase engagement. Furthermore, cleanness and spacious treatment rooms were mentioned by both employees and practitioners. The possibility to organise the working space and select instruments was mentioned as enhancing engagement, and impractical facilities and poor equipment were mentioned as decreasing engagement, as illustrated below:

In my profession, one of the most important things is the quality of equipment and staying in 'competition' [with regard to competitors]. In this medical specialty, development ahead is crucial, and, at this time, for example, the equipment for mammography is hopelessly out of date. I can't really recommend it for customers. Today, customers inquire about the age of equipment, for example, when they book an appointment and, of course, they will choose a company with newer and more modern equipment. (employee)

Some of the respondents also mentioned the location of the workplace and traffic connections as important for employee engagement.

\section{Discussion}

\section{Theoretical implications}

This study examined the link between employee engagement and internal branding to address the following research question: How are employee engagement and internal branding conceptually linked? In addition, the study sought to understand which antecedent factors 
healthcare professionals considered important for employee engagement. Consequently, the study adds to the scarce literature on the intersection of employee engagement and internal branding, particularly in the context of healthcare services (e.g. Gapp and Merrilees 2006; Heilmann 2010; Hytti et al. 2015; Lowe 2012). Three theoretical contributions of the study are discussed below.

As the first theoretical contribution, this study points out the connections between the concepts of employee engagement and internal branding and suggests that the antecedents of employee engagement are also elements of internal branding. This connection is confirmed by both the literature review and our analysis of the empirical data. In line with Lee et al. (2014), who argued that internal branding should precede employee engagement, our findings indicate that internal branding enhances employee engagement, and a lack of it may lead to contradictions and may negatively affect engagement. On the basis of the literature, seven categories representing antecedents of employee engagement were found: organisational culture, reward, working environment, training, HR practices, reputation and values and communication. These same categories were discovered from the internal branding literature, though described as elements. Furthermore, the connections were verified through empirical data. In addition, based on the empirical analysis, physical environment is suggested as an antecedent of employee engagement. The way in which healthcare professionals described the antecedents of employee engagement also reflected the elements of internal branding, which in this paper was defined as a strategic approach (e.g. Saleem \& Iglesias 2016) Although earlier literature has implicitly touched on these connections (Aggerholm et al. 2011; Lee et al. 2014; Davies et al. 2018), explicit reference to them is novel, showing that interdisciplinary research in this field enhances both literatures, employee engagement and internal branding, and provides a more holistic view to the joint phenomenon under examination. 
In general, the eight antecedent factors identified in this study support the view of Lee et al. (2014), who argued that internal branding aims to change employees at the cognitive and behavioural levels. However, their perspective views employees as somewhat passive targets of internal branding activities. By contrast, in line with Saleem and Iglesias (2016), we suggest that implementing a combination of internal branding elements is a strategic action that may enable employees to co-create the company's brand value, which is linked, for example, to the increasing meaningfulness of their work. Furthermore, our study discourages the view of identified factors solely as separate antecedents of employee engagement or tools of HRM (c.f. Maslach et al. 2001; Saks 2006) because they are linked to strategic actions in the intersection of HR and brand management. Accordingly, our study implies that pursuing a holistic (i.e. brand-centred) approach to HR and leadership nurtures employee engagement. Paying attention to both sides of the coin enables a more detailed understanding of the antecedents of employee engagement and provides a way to enhance employee engagement. Our study extends the findings of, for example, Saleem and Iglesias (2016) and Lee et al. (2014) by suggesting that these two sides of the same coin complement each other: employee engagement entails a nuanced and employee-centred approach, whereas internal branding ultimately embraces customer and stakeholder orientation while considering internal activities, directly or indirectly, that also affect external relationships. Furthermore, we suggest that internal branding has nuances according to which the brand either becomes more or less salient, through organisational management.

In line with some earlier studies (Schaufeli 2013), this study shows that employee engagement is a context-bound phenomenon: In professional services, certain antecedent factors of employee engagement, such as physical environment, may be context-specific, and engagement 
may be based on employees' roles. As its second theoretical contribution, this study adds to the employee engagement literature by suggesting that the eight identified antecedents of employee engagement are particularly important for professionals in healthcare organisations. Some of these factors reflect special features of the healthcare context. In the following, as an example, reputation and values and physical environment are briefly discussed.

With regard to reputation and values, professionals stated that their engagement would decrease notably if they were expected, for example, to prescribe antibiotics without medical justification, based solely on a customer's wishes. Thus, our study confirms the findings of earlier literature (e.g. Reay and Hinings 2009; Kippist and Fitzgerald 2009; Noordegraaf 2011; Croft, Currie, and Lockett 2015) that medical professionals typically have a strong indoctrination-based sense of what is ethical and justifiable. Accordingly, it is crucial for companies operating in the private sector to enable professionals to apply a logic they respect and to allow them to follow their core values. Preventing them from applying their professional logic is likely to cause conflict.

Furthermore, our results indicate that the physical environment is an antecedent of employee engagement. This antecedent may be context-specific and particularly important in healthcare. Although the reviewed literature did not emphasise it, the physical environment was particularly emphasised by practitioners, as reflected in terms of their discussions of obtaining value for the rent paid, keeping up with the competition and ensuring high-quality patient care. The relationship between physical environment and employee engagement has been discussed in the prior academic literature, for example, in architectural science, concentrating on green offices (McCunn \& Gifford 2012). Further, in the retailing context, there are studies concentrating on store design (e.g. Johnson et al. 2014), and the literature on service 
management pays attention to "servicescape" (e.g. Harris \& Ezeh 2008), but these studies concentrate on physical environment's effects on customers, not employees. Thus, our study adds understanding on the importance of physical environment in employee engagement, highlighting its particular importance in healthcare sector.

As the third theoretical contribution, this study adds to the rare intersection of literatures on employee engagement and internal branding, particularly in the context of healthcare services. Because both the employees and practitioners (entrepreneurs) worked for the same company, the studied case is interesting with regard to internal branding. As a special contextual feature, practitioners, specifically those who are physicians, usually represent more than one employer and healthcare brand simultaneously, because they often work both in public healthcare and for competing private sector organisations. The results indicate that this group is a challenging target for internal branding and, thus, employee engagement. Our study challenges the existing literature concerning employees' internalisation of a brand (e.g. Ind 2004), asking whether it is possible for a practitioner to 'live the brand' and become a true 'brand ambassador', even with effective internal branding, if he/she works for two or more organisations at the same time. In so doing, this study extends the very rare literature on the multi-employer perspective, particularly with regard to internal branding (or internalisation of a brand), but also with regard to employee engagement. In addition, patients tend to create relationships with healthcare professionals in person, not with the company. Our results indicate that the best-known practitioners may even be regarded as personal brands themselves, supporting findings from other fields (e.g. Blackston 2000). Interestingly, the results of this study indicate that physicians, particularly those who are working as independent practitioners, may engage more with the professional brand (i.e. the brand of their profession) than with the corporate brand of their healthcare organisation. This implies that in fields with strong professionalism, professional 
identity plays an important role with regard to employee engagement and internal branding activities.

Furthermore, with regard to employee engagement, when comparing employees and practitioners, this study suggests that employees are more critical of their employer but that practitioners may actually be less engaged. The study provides an opportunity to discuss whether various groups of personnel differ in terms of the factors that increase or decrease their engagement. Differences are understandable when considering employees' and practitioners' organisational roles and tasks. Although the above-mentioned antecedents are important for both employees and practitioners, there are some dissimilarities, as we have seen.

With regard to the connections between internal branding and employee engagement, our results suggest that brand management with too much of a focus on external stakeholders may be harmful to employee engagement, and that it is important for internal stakeholders to find brand communication appealing and comprehensible (see also Burmann and Zeplin 2005). This finding is in line with Machtiger (2004, p. 21), who described this challenge thus: 'While external marketing becomes more intricate, segmented and targeted, internal communications too often remain a blunt instrument'. Furthermore, our results imply that highlighting potential employees but dismissing current employees may damage employee engagement. This finding crystallises the importance of a strategic approach to internal branding (see Saleem and Iglesias 2016) to support internal stakeholders in their engagement and to encourage them to participate and to co-create and deliver the brand value of the company. 
On the basis of this study, we suggest that managers should consider both employee engagement, that is, the HR management perspective, and internal branding, that is, the strategic brand management perspective, for both to work in the organisation.

Our results indicate that internal branding should be carefully considered in healthcare organisations because the healthcare field seems to face challenges in terms of the division between employees and practitioners, on the one hand, and between physicians and other groups of healthcare professionals, on the other.

With respect to employee engagement, employees and practitioners may have different needs. For example, our data revealed that whereas employees complained about urgency and too many patients, practitioners were concerned about sufficient number of patients and adequate earning levels.

It would be beneficial for managers in the healthcare sector to pay extra attention to the planning of internal branding for personnel who work for more than one healthcare employer at the same time and who thus represent more than one employer brand simultaneously. In particular, it is important to educate these people about the distinguishing features of the healthcare brand in question. With regard to internal communication, in a multi-professional environment, the targeting of internal communication plans should be considered carefully (see also Welch 2011). Healthcare professionals may become frustrated if they receive numerous messages that are not relevant to their own unit or profession. Furthermore, healthcare professionals should seek clear and open communication. Welch (2011) has suggested that it would be useful to plan internal communications according to the varying levels of employee engagement. However, our results indicate that an even bigger challenge than targeting is ensuring that the necessary 
information is communicated to everyone. The healthcare professionals in this study expressed their disappointment at the lack of internal communication and mentioned the importance of feeling informed about what was happening in the workplace. For example, a lack of information about activities related to decreasing personnel may launch rumours, which could negatively affect employee engagement. Furthermore, the employees in our study indicated that it is important to feel that one's work is meaningful and to feel valued in workplace in order to be engaged. Bearing in mind Kahn's (1990) idea that engaged employees feel obligated to integrate themselves deeply into their role performance, we argue that internal branding could be employed to communicate with professionals about the value and relevance of their work for both the organisation and customers, thereby influencing employees' engagement and performance (see also Robertson and Cooper 2010).

Our findings indicate that representatives of healthcare professionals should be involved in designing marketing campaigns during the early stages of planning, as in development projects in general. Marketing campaigns typically remain uninternalised for employees if their representatives have not been involved in planning and if the employees have not been educated about the campaigns' aims. When decisions are made regarding, for example, advertising, it is important to ensure that they are communicated in a timely manner to every employee. Furthermore, managers should pay attention to the alignment of internal and external communication (see also Reed 1998).

The current data indicate that, in the case of a private healthcare organisation, physicians particularly those who are practitioners working entrepreneurially and paying rent to the company - may believe themselves to be considered internal customers by nurses and other staff. On the other hand, this seems to cause assistant personnel to feel unequal in relation to 
the physicians. In such situations, role-based engagement management might help to handle confrontations. Motivating career paths were considered important by the healthcare professionals in this study. However, caution in job advertisements is necessary to avoid promising too much; otherwise, new recruits may have overly optimistic expectations of their career paths, which could lead to disappointment and frustration later.

With regard to $H R$ practices, if an organisation wishes to pay attention to individualised employee engagement, low-level managers should be aware of the ways in which they can influence employees' personal-level engagement. Development discussions, for example, could provide a platform to discuss issues that enhance or prohibit engagement at a personal level; such discussions require education and alertness among managers, however. In addition, allowing employees and practitioners to plan their working spaces and tools could enhance employee engagement.

\section{Limitations and future studies}

The context of this study was one private healthcare organisation in one European country. Thus, it would be useful to examine the relationship between employee engagement and internal branding in other companies and countries, as different companies and national healthcare systems may offer additional knowledge on the topic. Further, studying the topic in the context of public healthcare might provide an additional understanding of this complex phenomenon. Extending the study to perceptions of potential employees should also yield beneficial information for both academics and practitioners on developing practices of employer branding (see e.g. Foster et al. 2010) and aligning them with those of internal branding. Including more 
specifically the physical environment's role in further studies on employee engagement and internal branding would be beneficial, as well.

This study provides a platform for discussion related to role-based engagement management within professional organisations. As Davies et al. (2018) note, an internal brand can be presented differentially to specific groups of employees to counter differences in how they respond to the same imagery and to counter any major differences in their levels of engagement. This idea yields useful paths for future studies, for example, in terms of studying how internal branding may best be customised for distinct groups of employees.

In particular, this study wishes to encourage further interdisciplinary studies of these concepts to achieve a more holistic picture of the phenomenon and surrounding issues. One direction could be research regarding actor engagement (e.g. Storbacka 2019), which, within the marketing domain, originally drew on employee (and brand) engagement to understand the phenomenon of multi-stakeholder engagement with service ecosystems.

\section{References:}

Aggerholm, H.K., Andersen, S.E. and Thomsen, C. (2011) Conceptualising employer branding in sustainable organisations. Corporate Communications: An International Journal 16(2): 105-123.

Anitha, J. (2014) Determinants of employee engagement and their impact on employee performance. International Journal of Productivity and Performance Management 63(3): $308-323$. 
Aurand, T. W., Gorchels, L., Terrence R. Bishop, T. R. (2005) Human resource management's role in internal branding: an opportunity for cross-functional brand message synergy. Journal of Product \& Brand Management 14(3): 163-169.

Beattie, R.S. and Waterhouse, J. (2015) Human Resource Management in Public Service Organizations. London: Routledge.

Bergstrom, A., Blumenthal, D. and Crothers, S. (2002) Why internal branding matters: The case of Saab. Corporate Reputation Review 5(2-3): 133-142.

Blackston, M. (2000) Observations: Building brand equity by managing the brand's relationships. Journal of Advertising Research 40(6): 101-105.

Boon, C., den Hartog, D.N., Boselie, P. and Paauwe, J. (2011) The relationship between perceptions of HR practices and employee outcomes: Examining the role of personorganisation and person-job fit. The International Journal of Human Resource Management 22(1): 138-162.

Braun, V. and Clarke, V. (2006) Using thematic analysis in psychology. Qualitative Research in Psychology, 3 (2): 77-101.

Burmann, C. and Zeplin, S. (2005) Building brand commitment: A behavioural approach to internal brand management. Journal of Brand Management 12(4): 279-300.

Croft, C., Currie, G. and Lockett, A. (2014) The impact of emotionally important social identities on the construction of a managerial leader identity: A challenge for nurses in the English National Health Service. Organization Studies 36(1), 113-131.

Dagher, G.K., Chapa, O. and Junaid, N. (2015) The historical evolution of employee engagement and self-efficacy constructs: An empirical examination in a non-western country. Journal of Management History 21(2): 232-256. 
Davies, G. and Chun, R. (2002) Gaps between the internal and external perceptions of the corporate brand. Corporate Reputation Review 5(2-3): 144-158.

Davies, G., Mete, M. and Whelan, S. (2018) When employer brand image aids employee satisfaction and engagement. Journal of Organizational Effectiveness: People and Performance 5(1), 64-80.

Dean, D., Arroy-Gamez, R.E., Punjaisri, K. and Pich, C. (2016) Internal brand co-creation: The experiential brand meaning cycle in higher education. Journal of Business Research 69(8): 3041-3048.

de Chernatony, L. and Harris, F. (2000) Developing corporate brands through considering internal and external stakeholders. Corporate Reputation Review 3(3): 268-274.

Dubois, A. \& Gadde, L.-E. (2002) Systematic combining: An abductive approach to case research. Journal of Business Research, 55(7), 553-560.

Edlinger, G. (2015) Employer brand management as boundary-work: A grounded theory analysis of employer brand managers' narrative accounts. Human Resource Management Journal 25(4): 443-457.

Elving, W.J.L., Westhoff, J.J.C., Meeusen, K. and Schoonderbeek, J.-W. (2013) The war for talent? The relevance of employer branding in job advertisements for becoming an employer of choice. Journal of Brand Management 20(5): 355-373.

Ewing, M.T., Pitt, L.F., de Bussy, N.M. and Berthon, P. (2002) Employment branding in the knowledge economy. International Journal of Advertising 21(1): 3-22. 
Fombrun, C.J., Ponzi, L.J. and Newburry, W. (2015) Stakeholder Tracking and Analysis: The RepTrak® System for Measuring Corporate. Corporate Reputation Review 18(1): 3-24.

Foster, C., Punjaisri, K. and Cheng, R. (2010) Exploring the relationship between corporate, internal and employer branding. Journal of Product \& Brand Management 19(6): 401409.

Gapp, R. and Merrilees, B. (2006) Important factors to consider when using internal branding as a management strategy: A healthcare case study. Journal of Brand Management 14(1-2): 162-176.

Grönroos, C. (2006) On defining marketing: finding a new roadmap for marketing. Marketing Theory, 6: 395-417.

Harris, L. C. \& Ezeh, C. (2008) Servicescape and loyalty intentions: an empirical investigation. European Journal of Marketing 42(3-4): 390-422.

Harter, J.K., Schmidt, F.L. and Hayes, T.L. (2002) Business-unit-level relationship between employee satisfaction, employee engagement, and business outcomes: A metaanalysis. Journal of Applied Psychology 87(2): 268-279.

Hatch, M. J., and Schultz, M. (1997). Relations between organizational culture, identity and image. European Journal of Marketing, 31(5): 356-365.

Heilmann, P.A.K. (2010) Employer brand image in a health care organization. Management Research Review 33(2): 134-144.

Hillebrandt, I. and Ivens, B.S. (2013) Scale development in employer branding. In: C. Baumgarth and D.M. Boltz (eds.) Impulse für die Markenpraxis und Markenforschung. Wiesbaden: Springer Gabler, pp. 65-86. 
Hytti, U., Kuoppakangas, P., Suomi, K., Chapleo, C. and Giovanardi, M. (2015) Challenges in delivering brand promise-Focusing on municipal healthcare organisations. International Journal of Public Sector Management 28(3): 254-272.

Iglesias, O., Ind, N. and Alfaro, M. (2013) The organic view of the brand: A brand value cocreation model. Journal of Brand Management 20(8): 670-688.

Ind, N. (2004) Living the brand: How to Transform Every Member of Your Organization into a Brand Ambassador. London: Kogan Page.

Iyer, P., Davari, A. and Paswan, A. (2018) Determinants of brand performance: the role of internal branding. Journal of Brand Management 25(3): 202-216.

Johnson, K. K.P., Kim H-Y, Mun, J. M. \& Lee, J. Y. (2014) Keeping customers shopping in stores: interrelationships among store attributes, shopping enjoyment, and place attachment. The International Review of Retail, Distribution and Consumer Research 25(1): 20-34.

Kahn, W.A. (1990) Psychological conditions of personal engagement and disengagement at work. Academy of Management Journal 33(4): 692-724.

Kippist, L. and Fitzgerald, A. (2009) Organisational professional conflict and hybrid clinician managers: The effects of dual roles in Australian healthcare organisations. Journal of Health Organization and Management 23(6): 642-655.

Kovácks, G. and Spens, K.M. (2005) Abductive reasoning in logistics research. International Journal of Physical Distribution \& Logistics 35(2): 132-144.

Kuoppakangas, P., Suomi, K., Clark, P., Chapleo, C. and Stenvall, J. (2019) Dilemmas in Rebranding a University__Maybe People Just Don’t Like Change”: Linking Meaningfulness and Mutuality into the Reconciliation. Corporate Reputation Review. https://doi.org/10.1057/s41299-019-00080-2. 
Lee, Y.-K., Kim, S. and Kim, S.Y. (2014) The impact of internal branding on employee engagement and outcome variables in the hotel industry. Asia Pacific Journal of Tourism Research 19(12): 1359-1380.

Lowe, G. (2012) How employee engagement matters for hospital performance. Healthcare Quarterly 15(2): 29-39.

Löhndorf, B. and Diamantopoulos, A. (2014) Internal branding - Social Identity and Social Exchange Perspectives on Turning Employees into Brand Champions. Journal of Service Research 17(3), 310-325.

Machtiger, B. (2004) Beware pitfalls that kill branding efforts. Marketing News, March 1: $21-22$.

Maslach, C., Schaufeli, W.B. and Leiter, M.P. (2001). Job burnout. Annual Review of Psychology 52(1): 397-422.

May, D. R.., Gilson, R. L. and Harter, L.M. (2004) The psychological conditions of meaningfulness, safety and availability and the engagement of the human spirit at work. Journal of Occupational and Organizational Psychology 77(1): 11-37.

McCunn, L.J and Gifford, R. (2012) Do green offices affect employee engagement and environmental attitudes? Journal Architectural Science Review 55(2): 128-134.

Mishra, K., Boynton, L. and Mishra, A. (2014) Driving employee engagement. International Journal of Business Communication 51(2): 183-202.

Mitchell, C. (2002) Selling the brand inside. Harvard Business Review. 80(1): 99-105.

Morokane, P., Chiba, M. and Kleyn, N. (2016) Drivers of employee propensity to endorse their corporate brand. Journal of Brand Management 23(1): 55-66. 
Merz, M.A., He, Y. and Vargo, S.L. (2009) The evolving brand logic: A service-dominant logic perspective. Journal of Academy of Marketing Science 37(3): 328-344.

Noordegraaf, M. (2011) Risky business. How professionals and professional fields (must) deal with organizational issues. Organization Studies 32(10): 1349-1371.

Patton, M. Q. (2002) Qualitative Research \& Evaluation Methods. $3^{\text {rd }}$ ed. Thousand Oaks, CA: Sage Publications.

Punjaisri, K., Evanschitzky, H. and Wilson, A. (2009a) Internal branding: An enabler of employees' brand-supporting behaviours. Journal of Service Management 20(2): 209226.

Punjaisri, K. and Wilson, A. (2007) The role of internal branding in the delivery of employee brand promise. Journal of Brand Management 15(1): 57-70.

Punjaisri, K. and Wilson, A. (2011) Internal branding process: Key mechanisms, outcomes and moderating factors. European Journal of Marketing 45(9-10): 1521-1537.

Punjaisri, K., A. Wilson, and H. Evanschitzky. (2008). Exploring the infuences of internal branding on employees' brand promise delivery. Journal of Relationship Marketing 7(4): $407-424$.

Punjaisri, K., Wilson, A. and Evanschitzky, H. (2009b) Internal branding to influence employees' brand promise delivery: A case study in Thailand. Journal of Service Management 20(5): 561-579.

Rana, S. (2015) High-involvement work practices and employee engagement. Human Resource Development International 18(3), 308-316. 
Rana, S., Ardichvili, A. and Tkachenko, O. (2014) A theoretical model of the antecedents and outcomes of employee engagement: Dubin's method. Journal of Workplace Learning 26 (3-4): 249-266.

Reay, T. and Hinings, C.R. (2009) Managing the rivalry of competing institutional logics. Organization Studies 30(6): 629-652.

Reed, D. (1998) Aligning internal and external communications to gain competitive advantage. Journal of Communication Management 2(3): 258-263.

Robertson, I.T. and Cooper, C. L. (2010) Full engagement: the integration of employee engagement and psychological well-being. Leadership \& Organization Development 31(4), 324-336.

Robinson, D., Perryman, S. and Hayday, S. (2004) The Drivers of Employee Engagement. Report 408. Institute for Employment Studies. Brighton: UK

Roper, S. and Fill, C. (2012) Corporate reputation-Brand and communication. Harlow, England: Pearson Education Limited.

Rothbard, N.R. (2001) Enriching or depleting? The dynamics of engagement in work and family roles. Administrative Science Quarterly 46: 655-684.

Saks, A.M. (2006) Antecedents and consequences of employee engagement. Journal of Managerial Psychology 21(7): 600-619.

Saleem, F.Z. and Iglesias, O. (2016) Mapping the domain of the fragmented field of internal branding. Journal of Product \& Brand Management 25(1): 43-57.

Schaufeli, W.B. (2013), What is Engagement? in Employee Engagement in Theory and Practice, eds. C. Truss, K. Alfes, R. Delbridge, A. Shantz, and E.C. Soane, London: Routledge. 
Schaufeli, W.B., Salanova, M., González-Romá, V. and Bakker, A.B. (2002) The measurement of engagement and burnout: A two sample confirmatory factor analytic approach. Journal of Happiness Studies 3(1): 71-92.

Storbacka, J. (2019) Actor engagement, value creation and market innovation. Industrial Marketing Management, 80: 4-10.

Sujchaphong, N., Nguyen, B. and Melewar, T.C. (2015) Internal branding in universities and the lessons learnt from the past: the significance of employee brand support and transformational leadership. Journal of Marketing for Higher Education 25(2): 204237.

Tanwar, K. and Prasad, A. (2016) The effect of employer brand dimensions on job satisfaction: gender as a moderator. Management Decision 54(4): 854-886.

Tuominen, S., Hirvonen, S., Reijonen, H. and Laukkanen, T. (2016) The internal branding process and financial performance in service companies: An examination of the required steps. Journal of Brand Management 23(3): 306-326.

Vallaster, C. \& de Chernatony, L. (2006) Internal brand building and structuration: the role of leadership. European Journal of Marketing 40(7-8): 761-784.

Wallström, Å., Karlsson, T. and Salehi-Sangari, E. (2008) Building a corporate brand: The internal brand building process in Swedish service firms. Journal of Brand Management 16(1-2): 40-50.

Welch, M. (2011) The evolution of the employee engagement concept: Communication implications. Corporate Communications: An International Journal 16(4): 328-346.

Whelan, S., Davies, G., Walsh, M. and Bourke, R. (2010) Public sector corporate branding and customer orientation. Journal of Business Research 63(11): 1164-1171.

Wollard, K. K., \& Shuck, B. (2011) Antecedents to employee engagement: A structured review of the literature. Advances in developing human resources 13(4): 429-446. 
Zeithaml, V.A., Bitner, M.J. and Gremler, D.D. (2012) Services Marketing: Integrating Customer Focus across the Firm. $6^{\text {th }}$ ed. New York: McGraw-Hill Irwin. 